\title{
DESEMPENHO E QUALIDADE DE CARCAÇA DE SUÍNOS MACHOS CASTRADOS, FÊMEAS E MACHOS IMUNOCASTRADOS DE DIFERENTES POTENCIAIS GENÉTICOS
}

Gustavo Freixo Rodrigues', Nikolas de Oliveira Amaral', Letícia Gomes de Morais Amaral', Lauro Francisco dos Santos' ${ }^{1}$, Marcos Lima Dias', Thaís Oliveira Silva', Helena Maria Fonseca da Silva², Ana Paula Cardoso Gomide $^{2}$

${ }^{1}$ Instituto Federal de Educação, Ciência e Tecnologia do Sul de Minas Gerais, Campus Machado, MG. ${ }^{2}$ Instituto Federal Goiano, Pós Graduação-Nível Mestrado, Campus Rio Verde, go. E-mail: helenafds@hotmail.com

\section{RESUMO}

Considerando o crescimento da imunocastração de suínos no Brasil e a carência de informações de seu efeito nas diferentes linhagens e cruzamentos comerciais, objetivou-se com este estudo avaliar o desempenho e a qualidade de carcaça de suínos de 70 a 150 dias de diferentes categorias sexuais e diferentes origens genéticas. Os machos reprodutores utilizados foram o PIET (com predominância da genética Pietrain) e o DLPH (proporção semelhante de Hampshire, Duroc, Large White, Pietrain). Foram utilizados 20 animais de cada categoria, com peso médio inicial de 25,0 kg alojados em baias de piso de concreto. Foi utilizado um delineamento experimental em blocos casualizados em arranjo fatorial $3 \times 2$ (três categorias sexuais - fêmeas, machos castrados e machos imunocastrados - e duas origens genéticas), totalizando seis tratamentos e cinco repetições, com dois animais por baia (parcela experimental). Os suínos DLPH apresentaram menor $(P<0,05)$ consumo de ração e conversão alimentar durante a fase de crescimento. Machos imunocastrados apresentaram melhor $(P<0,05)$ desempenho na fase de terminação. Não houve influência $(P>0,05)$ da origem genética sobre as características de carcaça, já o rendimento de carcaça de fêmeas foi superior $(P<0,05)$ ao de machos imunocastrados.

Palavras chave: bem estar; imunocastração; lucratividade.

\section{PERFORMANCE AND CARCASS QUALITY OF CASTRATED MALES, FEMALES AND IMMUNOCASTRATED MALE PIGS FROM DIFFERENT GENETIC POTENTIALS}

\begin{abstract}
Considering the growth of pig immunocastration in Brazil and the lack of information on its effects in the different lineages and commercial crosses, this study aimed to evaluate the performance and quality of pork carcass from 70 to 150 days of different sexual categories and different genetic origins. The breeding males used were PIET (predominantly Pietrain genetics) and DLPH (similar proportion of Hampshire, Duroc, Large White, Pietrain). Twenty animals of each category were used, with initial mean weight of $25.0 \mathrm{~kg}$ housed in concrete floor bays. A randomized block design in a $3 \times 2$ factorial arrangement (three sex categories - females, castrated males and immunocastrated males - and two genetic origins) was used, totaling six treatments and five replications, with two animals per bay (experimental plot). DLPH pigs presented lower $(\mathrm{P}<0.05)$ feed intake and feed conversion during the growth phase. Immunocastrated males showed better $(P<0.05)$ performance in the finishing phase. There was no influence $(P>0.05)$ of the genetic origin on the carcass traits and the carcass yield of females was higher $(P<0.05)$ than that of the immunocastrated males.
\end{abstract}

Keywords: wellbeing; immunocastration; profitability.

\section{INTRODUÇÃO}

O complexo agroindustrial da carne suína passou a investir em diversas tecnologias como forma de proporcionar maior eficiência produtiva, lucratividade, qualidade do produto final e bem-estar dos animais. Entre estas novas técnicas, destaca-se a imunocastração. Esta técnica consiste na utilização do próprio sistema 
imune dos animais para castrá-los, com a vantagem de permitir a atuação da testosterona na fase de crescimento, melhorando assim o desempenho, a relação carne/gordura na carcaça, além de atender a legislação vigente e ainda melhorar o bem-estar animal (SANTOS, 2012).

Além disso, de acordo com o método praticado na comercialização dos animais em cada região, a produção de suínos com diferentes potenciais genéticos deve ser vista como estratégia, uma vez que as empresas de melhoramento genético têm disponibilizado no mercado, reprodutores que imprimam em sua progênie, maior consumo e taxa de crescimento ou melhor eficiência alimentar e conformação de carcaça.

A capacidade de deposição de tecido magro que os suínos apresentam obedece à seguinte ordem decrescente: machos inteiros, fêmeas e machos castrados. Esta sequência é bastante considerada em outros países para a elaboração de dietas e para a otimização da nutrição de suínos em crescimento e terminação. Assim, a produção de suínos machos inteiros poderia ser interessante, pois a categoria tem maior potencial fisiológico para síntese proteica e melhor eficiência alimentar (PAULY et al., 2009).

Entretanto, sabe-se que machos inteiros deixam odor sexual na carcaça, prejudicando sua qualidade. Desta forma, para evitar a presença de odor sexual na carne, os leitões são submetidos nos primeiros dias de vida a um procedimento cirúrgico para a retirada dos testículos e são denominados como machos castrados cirurgicamente ou somente machos castrados. No entanto, a castração cirúrgica, por consistir na remoção dos testículos, provoca eliminação dos hormônios esteroides, impedindo o favorecimento de desempenho, além de ser um procedimento invasivo que causa problemas relacionados ao bem-estar animal (SANTOS, 2012).

Diante de pressões dos consumidores em relação ao bem-estar dos animais e das preferências quanto às características da carne, novas tecnologias têm sido adotadas para evitar a castração cirúrgica e viabilizar a produção de suínos machos inteiros (MILLET et al., 2011). A imunocastração destaca-se como uma destas alternativas (ZAMARATSKAIA; RASMUSSEN, 2015). A técnica consiste na vacinação dos animais com uma forma modificada do hormônio liberador de gonadotrofina $(\mathrm{GnRH})$ conjugada à uma proteína. A vacinação induz a formação de anticorpos direcionados contra o GnRH (ZAMARATSKAIA et al., 2008).

Assim, considerando o avanço da imunocastração de suínos no Brasil e a carência de informações de seu efeito nas diferentes linhagens e cruzamentos comerciais, foi realizado este estudo em que objetivou-se avaliar o desempenho e a qualidade de carcaça de suínos machos imunocastrados em comparação a fêmeas e machos castrados oriundos de cruzamentos envolvendo machos reprodutores com diferentes potenciais para ganho de peso ou síntese de carne magra.

\section{MATERIAL E MÉTODOS}

\section{Local de realização do experimento}

A pesquisa foi conduzida na Unidade Educativa de Produção de Suínos do Instituto Federal de Educação, Ciência e Tecnologia do Sul de Minas Gerais (IFSULDEMINAS), Campus Machado - MG.

\section{Animais e instalações}

A metodologia aplicada no presente estudo foi aprovada pelo Comitê de Ética no Uso de Animais (CEUA) do IFSULDEMINAS, parecer no 02/A 2015.

Foram utilizados 60 suínos dos 70 aos 150 dias, sendo 20 machos imunocastrados, 20 machos castrados cirurgicamente e 20 fêmeas. Para a avaliação de carcaça foi utilizado apenas 1 animal da parcela experimental, escolhido de acordo com a média de peso do tratamento. Foram avaliadas as progênies oriundas do cruzamento entre uma matriz comercial e dois reprodutores de diferentes potenciais para taxa de ganho de peso ou síntese de carne magra. Os machos reprodutores utilizados foram o PIET (com predominância da genética Pietrain e caracterizado por imprimir em sua progênie maior taxa de ganho de peso) e o DLPH (proporção semelhante de Hampshire, Duroc, Large White, Pietrain, caracterizado por imprimir em sua progênie maior síntese de carne magra). Os animais foram alojados em baias com dois animais (parcela experimental), em instalações de crescimento e terminação com baias de piso de concreto $\left(2,0 \times 1,5 \mathrm{~m}^{2}\right)$, dotadas de comedouros manuais e bebedouros tipo chupeta.

\section{Delineamento experimental}

$O$ delineamento experimental utilizado foi em blocos casualizados, em arranjo fatorial $3 \mathrm{x}$ 
2 (três categorias sexuais - fêmeas, machos castrados e machos imunocastrados - e duas origens genéticas - macho PIET e macho DLPH), totalizando seis tratamentos e cinco repetições, com dois animais por parcela experimental.

Para a qualidade de carcaça, foi utilizado um animal da parcela experimental, totalizando 30 animais.

\section{Procedimento experimental}

Antes do início do experimento foram obedecidas as normas usuais para limpeza e desinfecção do galpão de 17 dias, sendo dois para limpeza e 15 para vazio sanitário com pulverização de desinfetante a base de amônia quaternária e glutaraldeído.

As dietas foram formuladas a base de milho e farelo de soja, suplementadas com vitaminas e minerais de forma a atender as exigências mínimas sugeridas por (Rostagno et al., 2011).

A castração cirúrgica dos machos foi realizada de acordo com o protocolo padrão realizado nas granjas comerciais: entre sete e dez dias de idade. Já a imunocastração foi realizada a partir da aplicação de duas doses da vacina comercial VIVAX (Zoetis Brasil, Campinas/SP), sendo a primeira realizada aos 93 dias de idade dos animais e a segunda 28 dias após.

Os animais foram alojados em duplas (parcela experimental), a partir dos 70 dias de idade, em galpão de crescimento e terminação com baias de piso concreto $(2,0$ metros $\times 1,5$ metros), dotadas de comedouros manuais $\mathrm{e}$ bebedouros tipo chupeta. As dietas foram fornecidas à vontade, durante todo o período experimental. Os suínos foram pesados no início, aos 121 dias (data da segunda dose da vacina) e no final do experimento, para a determinação do ganho de peso. Diariamente, foi realizada a limpeza das baias e, duas vezes ao dia, a ração foi fornecida e os desperdícios foram pesados para a determinação do consumo de cada animal.
Assim, as variáveis analisadas para o desempenho foram peso final, consumo de ração médio diário, ganho de peso médio diário e conversão alimentar, para as fases de crescimento (70 aos 121 dias) e terminação (121 aos 150 dias).

Ao final do período experimental os animais foram submetidos ao jejum sólido, por 12 horas e, posteriormente, foram abatidos e eviscerados para a avaliação das carcaças. Logo após a evisceração, as carcaças foram serradas longitudinalmente ao meio e pesadas. A meia carcaça esquerda de cada suíno foi resfriada a uma temperatura média de 7 으, durante 24 horas, para posterior avaliação das características da mesma. As variáveis analisadas foram espessura de toucinho, profundidade de lombo, área de olho de lombo, rendimento de carcaça, rendimento de carne na carcaça e quantidade de carne na carcaça resfriada. A determinação do rendimento de carne na carcaça resfriada foi realizada por meio de análise de predição conforme a fórmula descrita por Guidoni (2000).

Os dados referentes à origem dos animais avaliados, bem como às demais atividades de gerenciamento da Unidade Educativa foram registrados e analisados através do software AGRINESS S2 COMERCIAL.

\section{Análises estatísticas}

A avaliação estatística foi através do programa SISVAR, sendo os dados submetidos à análise de variância (ANOVA), o teste $F$ utilizado para comparar as genéticas e o teste Tukey para comparar as categorias sexuais, ambos com $5 \%$ de significância, isolados ou dentro da interação, quando significativa.

\section{RESULTADOS E DISCUSSÃO}

Os resultados de desempenho para a fase de crescimento estão descritos na tabela a seguir (Tabela 1). 
Tabela 1. Desempenho de suínos de diferentes categorias sexuais (fêmeas, machos castrados e machos imunocastrados) com diferentes potenciais para ganho de peso dos 70 aos 121 dias.

\begin{tabular}{|c|c|c|c|c|c|c|c|}
\hline \multirow[b]{2}{*}{ Genética } & \multicolumn{3}{|c|}{ Categoria Sexual } & \multirow[b]{2}{*}{ Média* } & \multirow{2}{*}{$\begin{array}{c}P \\
\text { Sexo }\end{array}$} & \multirow{2}{*}{$\begin{array}{l}P \\
\text { Gen }\end{array}$} & \multirow{2}{*}{$\begin{array}{c}P \\
S^{*} G\end{array}$} \\
\hline & Fêmea & $\begin{array}{l}\text { Macho } \\
\text { Castrado }\end{array}$ & $\begin{array}{c}\text { Macho } \\
\text { Imunocastrado }\end{array}$ & & & & \\
\hline \multicolumn{8}{|c|}{ Peso Inicial (Kg) } \\
\hline PIET & 24,84 & 25,56 & 25,04 & 25,15 & \multirow[t]{2}{*}{0,4188} & \multirow[t]{2}{*}{0,4549} & \multirow[t]{2}{*}{0,9626} \\
\hline DLPH & 24,48 & 25,13 & 24,88 & 24,83 & & & \\
\hline Média & 24,66 & 25,35 & 24,96 & & & & \\
\hline CV (\%) & 4,56 & & & & & & \\
\hline \multicolumn{8}{|c|}{ Peso Final ( $\mathrm{kg})$} \\
\hline PIET & 66,68 & 71,64 & 67,81 & 68,71 & \multirow{2}{*}{0,1390} & \multirow{2}{*}{0,3033} & \multirow{2}{*}{0,6558} \\
\hline DLPH & 66,9 & 69,41 & 63,51 & 66,61 & & & \\
\hline Média & 66,79 & 70,52 & 65,66 & & & & \\
\hline CV (\%) & 8,06 & & & & & & \\
\hline \multicolumn{8}{|c|}{ Ganho de peso médio diário (kg) } \\
\hline PIET & 0,82 & 0,90 & 0,84 & 0,854 & \multirow{2}{*}{0,1739} & \multirow{2}{*}{0,3604} & \multirow{2}{*}{0,6072} \\
\hline DLPH & 0,83 & 0,87 & 0,76 & 0,819 & & & \\
\hline Média & 0,826 & 0,885 & 0,798 & & & & \\
\hline CV (\%) & 12,26 & & & & & & \\
\hline \multicolumn{8}{|c|}{ Consumo de ração médio diário $(\mathrm{kg})$} \\
\hline PIET & 2,66 & 2,74 & 2,67 & $2,690 \mathrm{~b}$ & \multirow{2}{*}{0,5985} & \multirow{2}{*}{0,0357} & \multirow{2}{*}{0,8848} \\
\hline DLPH & 2,52 & 2,58 & 2,58 & $2,559 a$ & & & \\
\hline Média & 2,589 & 2,663 & 2,622 & & & & \\
\hline CV (\%) & 6,10 & & & & & & \\
\hline \multicolumn{8}{|c|}{ Conversão alimentar ( $\mathrm{kg} / \mathrm{kg})$} \\
\hline PIET & 3,39 & 3,06 & 3,20 & $3,218 b$ & \multirow{2}{*}{0,2516} & \multirow{2}{*}{0,0533} & \multirow{2}{*}{0,5055} \\
\hline DLPH & 3,05 & 2,99 & 3,04 & $3,024 a$ & & & \\
\hline Média & 3,22 & 3,02 & 3,12 & & & & \\
\hline CV (\%) & 8,29 & & & & & & \\
\hline
\end{tabular}

*Médias seguidas de letras diferentes na coluna diferem entre si pelo teste Tukey $(\mathrm{P}<0,05)$.

Não foram observadas diferenças significativas $(P>0,05)$ para a categoria sexual dos animais nessa fase, porém a origem genética dos animais influenciou $(P<0,05)$ o consumo de ração médio diário (CRMD) e a conversão alimentar (CA) que foram melhores para os animais DLPH. Em função da característica que imprimem em sua progênie, estes resultados eram esperados para os animais PIET. No entanto, na fase subsequente essa diferença não foi observada $(P>0,05)$.

Com relação à categoria sexual, foi observado na fase de terminação (Tabela 2) que machos imunocastrados apresentaram maior $(\mathrm{P}<$ $0,05)$ peso final e ganho de peso médio diário, além de uma melhor $(P<0,05)$ conversão alimentar. 
Tabela 2. Desempenho de suínos de diferentes categorias sexuais (fêmeas, machos castrados e machos imunocastrados) com diferentes potenciais para ganho de peso dos 121 aos 150 dias.

\begin{tabular}{|c|c|c|c|c|c|c|c|}
\hline \multirow[b]{2}{*}{ Genética } & \multicolumn{3}{|c|}{ Categoria Sexual } & \multirow[b]{2}{*}{ Média } & \multirow{2}{*}{$\begin{array}{c}P \\
\text { Sexo }\end{array}$} & \multirow{2}{*}{$\begin{array}{c}P \\
\text { Gene }\end{array}$} & \multirow{2}{*}{$\begin{array}{c}P \\
S * G\end{array}$} \\
\hline & Fêmea & $\begin{array}{l}\text { Macho } \\
\text { Castrado }\end{array}$ & $\begin{array}{c}\text { Macho } \\
\text { Imunocastrado }\end{array}$ & & & & \\
\hline \multicolumn{8}{|c|}{ Peso Final (kg) } \\
\hline PIET & 91,55 & 98,99 & 99,15 & 96,56 & \multirow{2}{*}{0,0011} & \multirow{2}{*}{0,5618} & \multirow{2}{*}{0,7049} \\
\hline $\mathrm{DLPH}$ & 92,42 & 98,31 & 101,89 & 97,54 & & & \\
\hline Média* & $91,98 a$ & $98,64 b$ & $100,52 b$ & & & & \\
\hline CV (\%) & 4,67 & & & & & & \\
\hline \multicolumn{8}{|c|}{ Ganho de peso médio diário (kg) } \\
\hline PIET & 0,89 & 0,98 & 1,12 & 0,996 & \multirow{2}{*}{0,0003} & \multirow{2}{*}{0,2253} & \multirow{2}{*}{0,8117} \\
\hline DLPH & 0,91 & 1,03 & 1,21 & 1,050 & & & \\
\hline Média* & $0,898 a$ & $1,004 a$ & $1,164 b$ & & & & \\
\hline CV (\%) & 11,79 & & & & & & \\
\hline \multicolumn{8}{|c|}{ Consumo de ração médio diário (kg) } \\
\hline PIET & 3,37 & 3,52 & 3,47 & 3,449 & \multirow{2}{*}{0,2805} & \multirow{2}{*}{0,7922} & \multirow{2}{*}{0,4762} \\
\hline DLPH & 3,44 & 3,53 & 3,33 & 3,430 & & & \\
\hline Média & 3,403 & 3,522 & 3,395 & & & & \\
\hline CV (\%) & 5,62 & & & & & & \\
\hline \multicolumn{8}{|c|}{ Conversão alimentar $(\mathrm{kg} / \mathrm{kg})$} \\
\hline PIET & 3,88 & 3,66 & 3,15 & 3,567 & \multirow{2}{*}{0,0001} & \multirow{2}{*}{0,2470} & \multirow{2}{*}{0,5689} \\
\hline DLPH & 3,91 & 3,49 & 2,81 & 3,402 & & & \\
\hline Média* & $3,897 a$ & $3,573 a b$ & $2,985 b$ & & & & \\
\hline CV (\%) & 10,85 & & & & & & \\
\hline
\end{tabular}

*Médias seguidas de letras diferentes na linha diferem entre si pelo teste Tukey $(P<0,05)$.

Esses resultados estão de acordo com outros dados da literatura (BRUNO, 2012; PAULY et al., 2009), em que o ganho de peso médio diário de animais imunocastrados foi superior ao de machos castrados. Além disso, também foi observado por Morales et al. (2012), melhor conversão alimentar de machos imunocastrados em relação a fêmeas e machos castrados.

Em outro trabalho, Aluwé et al. (2016) comparou diferentes momentos de imunocastração antes do abate e, independente disso, as fêmeas apresentaram menor consume de ração médio diário e ganho de peso médio diário ao final da fase de terminação e maior conversão alimentar do que machos imunocastrados em qualquer momento.

Sabe-se que os suínos machos inteiros têm melhor capacidade de converter os alimentos em músculo, o que ocorre devido às ações dos hormônios de crescimento somatotróficos. Alguns esteroides como o androstenediol, a dihidropiandrosterona e a testosterona podem atuar na retenção de nitrogênio e no crescimento muscular (LANTHIER et al., 2006). Neste sentido, machos imunocastrados são beneficiados por estas características de crescimento do macho inteiro até a aplicação da segunda dose da vacina e, mais tarde, pelo ganho relacionado à maior ingestão de alimento e ao efeito anabólico residual (DUNSHEA et al., 2001).

Apesar dos dados de desempenho, há importância em verificar os impactos disso na qualidade de carcaça. Os resultados avaliados na qualidade de carcaça dos animais estão apresentados na tabela 3 . 
Tabela 3. Avaliação de carcaça de suínos de diferentes categorias sexuais (fêmeas, machos castrados e machos imunocastrados) com diferentes potenciais para ganho de peso aos 150 dias de idade

\begin{tabular}{|c|c|c|c|c|c|c|c|}
\hline \multirow[b]{2}{*}{ Genética } & \multicolumn{3}{|c|}{ Categoria Sexual } & \multirow[b]{2}{*}{ Média } & \multirow{2}{*}{$\begin{array}{c}\mathrm{P} \\
\text { Gene }\end{array}$} & \multirow{2}{*}{$\begin{array}{c}P \\
\text { Sexo }\end{array}$} & \multirow{2}{*}{$\begin{array}{c}P \\
G * S\end{array}$} \\
\hline & Fêmea & $\begin{array}{l}\text { Macho } \\
\text { Castrado }\end{array}$ & $\begin{array}{c}\text { Macho } \\
\text { Imunocastrado }\end{array}$ & & & & \\
\hline \multicolumn{8}{|c|}{ Espessura de toucinho $(\mathrm{mm})$} \\
\hline PIET & 9,8 & 11,0 & 7,6 & 9,1 & \multirow{2}{*}{0,7626} & \multirow{2}{*}{0,2143} & \multirow{2}{*}{0,1121} \\
\hline DLPH & 6,3 & 10,4 & 10,5 & 9,5 & & & \\
\hline Média & 8,1 & 10,7 & 9,1 & & & & \\
\hline CV (\%) & 35,35 & & & & & & \\
\hline \multicolumn{8}{|c|}{ Profundidade de lombo $(\mathrm{mm})$} \\
\hline PIET & 63,3 & 62,7 & 63,4 & 63,1 & \multirow{2}{*}{0,2869} & \multirow{2}{*}{0,8814} & \multirow{2}{*}{0,7917} \\
\hline DLPH & 61,9 & 62,0 & 59,8 & 61,2 & & & \\
\hline Média & 62,7 & 62,3 & 61,6 & & & & \\
\hline CV (\%) & 7,67 & & & & & & \\
\hline \multicolumn{8}{|c|}{ Área de olho de lombo $\left(\mathrm{cm}^{2}\right)$} \\
\hline PIET & 46,2 & 45,5 & 45,2 & 36,5 & \multirow{2}{*}{0,9888} & \multirow{2}{*}{0,8983} & \multirow{2}{*}{0,9945} \\
\hline DLPH & 46,2 & 45,3 & 45,4 & 36,5 & & & \\
\hline Média & 37,0 & 36,3 & 36,2 & & & & \\
\hline CV (\%) & 10,92 & & & & & & \\
\hline \multicolumn{8}{|c|}{ Rendimento de carcaça (\%) } \\
\hline PIET & 79,1 & 78,3 & 77,8 & 78,38 & \multirow{2}{*}{0,7517} & \multirow{2}{*}{0,0255} & \multirow{2}{*}{0,4388} \\
\hline DLPH & 79,1 & 79,2 & 77,3 & 78,53 & & & \\
\hline Média* & $79,10 b$ & $78,74 a b$ & $77,55 a$ & & & & \\
\hline CV (\%) & 1,59 & & & & & & \\
\hline \multicolumn{8}{|c|}{ Rendimento de carne na carcaça (\%) } \\
\hline PIET & 63,2 & 62,4 & 64,6 & 63,38 & \multirow{2}{*}{0,9703} & \multirow{2}{*}{0,2158} & \multirow{2}{*}{0,1127} \\
\hline DLPH & 65,5 & 62,5 & 62,2 & 63,41 & & & \\
\hline Média & 64,34 & 62,44 & 63,40 & & & & \\
\hline CV (\%) & 3,67 & & & & & & \\
\hline \multicolumn{8}{|c|}{ Quantidade de carne na carcaça fria $(\mathrm{kg})$} \\
\hline PIET & 45,4 & 44,8 & 50,2 & 46,77 & 0,4745 & 0,1149 & 0,1869 \\
\hline DLPH & 47,7 & 47,4 & 47,8 & 47,62 & & & \\
\hline Média & 46,52 & 46,08 & 49,00 & & & & \\
\hline CV (\%) & 6,79 & & & & & & \\
\hline
\end{tabular}

*Médias seguidas de letras diferentes na linha diferem entre si pelo teste Tukey $(P<0,05)$.

Não houve efeito $(P>0,05)$ da origem genética sobre as variáveis analisadas, porém fêmeas apresentaram maior $(P=0,03)$ rendimento de carcaça $(\mathrm{RC})$ do que machos imunocastrados (MI).

Em um trabalho semelhante, Bruno (2012) verificou que grande parte das variáveis de carcaça permaneceram semelhantes entre machos castrados (MC) e imunocastrados, da mesma forma que os resultados encontrados nessa pesquisa. Por outro lado, esses autores observaram maior RC de $\mathrm{MI}$ em comparação aos $M C$, sendo que nessa pesquisa essa variável foi semelhante para estas categorias sexuais.

Por outro lado, Caldara et al. (2013) observou menor espessura de toucinho em 
machos imunocastrados, ainda assim não interferindo na qualidade da carne de suínos de médio potencial genético para deposição de carne magra, uma vez que a genética utilizada foi uma mistura de Large White e Landrace.

De forma geral, tem sido relatado menor rendimento de carcaça de $\mathrm{Ml}$ em comparação com MC em outros trabalhos na literatura. Pauly et al. (2009) observaram que $\mathrm{Ml}$ e machos inteiros apresentam menor RC do que MC. Da mesma forma que Braña et al. (2013) verificaram menor RC para MI do que MC, associado a uma maior porcentagem de carne magra na carcaça.

Independentemente da categoria sexual ou origem genética, os animais receberam a mesma dieta. Isto pode ter contribuído para os resultados obtidos uma vez que animais com alto potencial para síntese de carne magra, respondem melhor quando alimentados com dietas contendo elevados níveis de nutrientes. Assim, considerando a escassez de informações na literatura brasileira em relação às exigências nutricionais de suínos machos imunocastrados, faz-se necessário mais estudos para estabelecer níveis adequados para os suínos de acordo com seu potencial genético.

\section{CONCLUSÃO}

Suínos de origem DLPH apresentaram menor consumo e conversão alimentar na fase de crescimento. Suínos machos imunocastrados apresentam melhor desempenho na fase de terminação que machos castrados e fêmeas.

As características de carcaça de suínos não foram influenciadas pelas origens genéticas estudadas. $O$ rendimento de carcaça de fêmeas foi superior ao de machos imunocastrados.

\section{AGRADECIMENTOS}

Agradecemos ao Instituto Federal do Sul de Minas Gerais - Campus Machado pela concessão das instalações experimentais e bolsas de estudo; e à empresa Agriness LTDA, pela disponibilização do software Agriness S2.

\section{REFERÊNCIAS}

ALUWÉ, M.; DEGEZELLE, I.; DEPUYDT, L.; FREMAUT, D.; VAN DEN BROEKE, A.; MILLET, S. Immunnocastrated male pigs: effect of 4 v. 6 weeks time post second injection on performance, carcass quality and meat quality. Animal, v. 10, n. 9, p. 1466-1473, 2016. https://doi.org/10.1017/S1751731116000434
BRAÑA, D. V.; ROJO-GÓMES, G. A.; ELLIS, M.; CUARON, J. A. Effect of gender (gilt and surgically and immunocastrated male) and ractopamine hydrochloride supplementation on growth performance, carcass, and pork quality characteristics of finishing pigs under commercial conditions. Journal of animal science, v. 91, n. 12, p. 5894-5904, abril, 2013. https://doi.org/10.2527/jas.2013-6545

BRUNO, H. V. 2012. Avaliação técnico-econômica de suínos machos imuno e cirurgicamente castrados. Campo Grande - MS, 2012. 38p.

CALDARA, F. R.; MOI, M.; SANTOS, L. S.; PAZ, I. C. L. A.; GARCIA, R. G.; NAAS, I. A. et al. Carcass characteristics and qualitative attributes of pork from immunocastrated animals. AsianAustralasian Journal of animal Science, v. 26, n. 11, p. 1630-1636, 2013.

DUNSHEA, F.R.; COLANTONI, C.; HOWARD, K.; MCCAULEY, I.; JACKSON, P.; LONG, K.A.; LOPATICKI, S. Vaccination of boars with a Gnrh vaccine (improvac) eliminates boar taint and increases growth performance. Journal of animal science, v.79, p.2524-2535, 2001. https://doi.org/10.2527/2001.79102524x

GUIDONI, A. L. Melhoria de processos para a tipificação e valorização de carcaças suínas no brasil. In: conf. Int. Virtual sobre qual. De carne suína. Embrapa suínos e aves, Concórdia, SC, 2000. 14p.

LANTHIER, F. et al. Characterizing developmental changes in plasma and tissue skatole concentrations in the prepubescent intact male pig. Journal of Animal Science, Rockville, v. 84, n. 6 , p. 1699-1708, Jun. 2006. https://doi.org/10.2527/jas.2005-633

MILLET, S.; GIELKENS, K.; DE BRABANDER, D.; JANSSENS, G. P. Considerations on the performance of immunocastrated male pigs. Animal, v. 5, n. 7, p. 1119-1123, 2011. https://doi.org/10.1017/S1751731111000140

MORALES, J. I.; SERRANO, M. P.; CÁMARA, L.; BERROCOSO, J. D.; LÓPEZ, J. P.; MATEOS, G. G. Growth performance and carcass quality of immunocastrated and surgically castrated pigs from crossbreds from duroc and pietrain sires. Journal of animal science, v. 91, n. 8, p. 3955- 
3964, 2012. https://doi.org/10.2527/jas.2012-

$\underline{6068}$

PAULY, C.; SPRING, P.; O'DOHERTY, J. V.; AMPUERO KRAGTEN, S.; BEE, G. Growth performance, carcass characteristics and meat quality of group-penned surgically castrated, immunocastrated (improvacr) and entire male pigs and individually penned entire male pigs. Animal, v. 3, n. 7, p. 1057-1066, 2009. https://doi.org/10.1017/S1751731109004418

ROSTAGNO, H. S.; ALBINO, L. F. T.; DONZELE, J .L.; GOMES, P. C.; OLIVEIRA, R. F.; LOPES, D. C. et al. Tabelas brasileiras para aves e suínos: composição de alimentos e exigências nutricionais de aves e suínos. 3. edição, Viçosa, Minas Gerais: UFV, 252 p., 2011.

SANTOS, A.P; KIEFER, C.; MARTINS, L.P. et al. Restrição alimentar para suínos machos castrados e imunocastrados em terminação. Ciência rural, v.42, p.147-153, 2012. https://doi.org/10.1590/S0103$\underline{84782012000100024}$

ZAMARATSKAIA, G.; ANDERSSON, H.K.; CHEN, G.; ANDERSSON, K.; MADEJ, A.; LUNDSTROM, K. Effect of a gonadotropin-releasing hormone vaccine (improvac) on steroid hormones, boar taint compounds and performance in entire male pigs. Reproduction in domestic animals, v.43, p.351-359, 2008. https://doi.org/10.1111/j.1439$\underline{0531.2007 .00914 . x}$

ZAMARATSKAIA, G.; RASMUSSEN, $M . \quad K$. Immunocastration of male pigs - situation today. Procedia Food Science, v. 5, p. 324-327, 2015. https://doi.org/10.1016/i.profoo.2015.09.064

Recebido para publicação em 15/08/2017

Revisado em 05/12/2017

Aceito em 09/02/2018 